\title{
Radiation safety requirements for training of users of diagnostic X-ray equipment in South Africa
}

\author{
B van der Merwe, ${ }^{1} \mathrm{PhD} ; \mathbf{S}$ B Kruger, ${ }^{2} \mathrm{PhD} ; \mathbf{M} \mathbf{M}$ Nel, ${ }^{2} \mathrm{PhD}$ \\ ${ }^{1}$ Department of Clinical Sciences, Central University of Technology, Bloemfontein, South Africa \\ ${ }^{2}$ Division of Health Sciences Education, Faculty of Health Sciences, University of the Free State, Bloemfontein, South Africa
}

Corresponding author: B van der Merwe (bevdmerwe@cut.ac.za)

Background. Globally, the aim of requirements regarding the use and ownership of diagnostic medical X-ray equipment is to limit radiation by abiding by the 'as low as reasonably achievable' (ALARA) principle. The ignorance of radiographers with regard to radiation safety requirements, however, is currently a cause of concern. The enhancement of the 4-year radiography curriculum leading to a Bachelor's qualification provides an opportunity to explore the training and assessment to meet, among others, the ALARA principle, which addresses national and international concerns and criteria. Healthcare workers outside the scope of radiography, who are also considered radiation workers, may be even more ignorant and are therefore also implicated. The process of investigation included a contextualisation of the available regulation documents, the Delphi technique to determine the content of the training, and a questionnaire to test students' knowledge before and after training.

Objectives. To determine the content of the radiation safety requirements training and assessment to implement standardised teaching, learning activities and assessment to prepare radiographers as radiation workers well trained for practice.

Methods. The content of the radiation safety requirements training was determined with the Delphi technique.

Results. Consensus regarding the content of the radiography students' training was reached and implemented. Furthermore, it guided the development of teaching and learning activities complemented by aligned assessment.

Conclusion. Standardised education and assessment for radiation safety requirements have the potential to ensure that radiation safety regulations are implemented optimally in diagnostic imaging.

Afr J Health Professions Educ 2017;9(3):123-127. DOI:10.7196/AJHPE.2017.v9i3.691

The importance of radiation safety training was reiterated by the World Health Organization (WHO). In 2007, World Health Assembly (WHA) Resolution 60.29 urged the WHO to 'draw up guidelines to ensure the quality, safety and efficacy of medical devices. ${ }^{\left[{ }^{1]}\right.}$ Annually, millions of X-ray examinations are done worldwide and, therefore, the benefit/risk balance of every examination should always be considered. The education of radiation workers has the potential to change behaviour to implement a culture of safe patient care. It is important that procedures and requirements are easily understood by health professionals. ${ }^{[1]}$

Not complying with the regulations of safety has often been observed by the principal researcher (BvdM) in clinical practice and is increasingly a matter of great concern. To comply with minimum safety regulation criteria, the entry-level radiography student, placed in clinical practice during the first weeks of training, needs education regarding the safety requirements before being occupationally exposed to radiation. The same applies to radiography students in their $2 \mathrm{nd}$ - 4 th year, whose safety is the responsibility of the licence holder of medical X-ray equipment. One should also take into consideration that the radiography student may apply to procure X-ray equipment upon graduation, which emphasises the imperative for a training model that will ensure $100 \%$ compliance to international standards.

Recently, the International Atomic Energy Agency (IAEA) made important international recommendations to promote a safety culture by motivating commitment to protection and safety at all levels. Radiation safety participation must be encouraged and accountability ensured, which implies that a learning attitude should be promoted to carry out tasks safely. ${ }^{[2]}$
The International Commission on Radiological Protection (ICRP) is the primary body for protection against ionising radiation, created by the 1928 International Congress of Radiology to promote radiological protection as a public interest. The ICRP publishes quarterly recommendations on and guidance in protection against the risks associated with ionising radiation in Annals of the ICRP. Each issue provides in-depth coverage of a specific subject area. ${ }^{[3]}$ The commission has made basic recommendations for education and training of medical staff in ICRP publications 103 and 105. ${ }^{[4]}$ Publication 113 provides guidance regarding the necessary radiological protection education and training for use by regulators, industry and institutions educating professionals involved in radiation in healthcare. ${ }^{[3]}$

In the context of the ICRP publication, ${ }^{[5]}$ the term 'education' refers to imparting knowledge and understanding of radiation health effects, regulation, and factors in practice affecting patient and staff doses. It has been suggested that the education should be part of the curriculum of medical, dental, radiography and other healthcare specialists, such as radiologists and medical physicists. The term 'training' is defined as coaching with regard to radiological protection for the justified application of modalities (e.g. computed tomography (CT), fluoroscopy) that a healthcare worker uses in medical practice. ${ }^{[5]}$

Having provided an international perspective, it is important to consider the local scenario. The South African (SA) Department of Health (DoH) accepted the recommendations of the ICRP and regulates radiation protection within the framework of the Hazardous Substances Act No. 15 
of $1973 .{ }^{[4]}$ This act stipulates that the Minister of Health, and specifically the Director-General of Health, may issue licences to manufacturers, importers and users of electromedical (X-ray) equipment. X-ray equipment comprises electronic products (X-rays) and is considered a Group III hazardous substance. Group III hazardous substances are regulated by Regulation 1332 (regulations concerning the control of electronic products). ${ }^{[6]}$ The SA DoH applies international standards as requirements and guidelines through the Directorate Radiation Control (DRC). The DRC issues a licence if the product and usage comply with the legislative and international requirements for safety and performance. ${ }^{[4]}$ Two documents are effective when a licence is issued, i.e.: ( $i$ ) 'Code of practice for users of medical X-ray equipment'; ${ }^{[7]}$ and (ii) 'Requirements for licence holders with respect to quality-control tests for diagnostic X-ray imaging systems. ${ }^{[8]}$

The requirements in these two documents were contextualised as criteria in the Delphi document to determine the content of the training for radiography students. It is important that radiographers as radiation workers and users of X-ray equipment are aware of the legislation and regulations underpinning the use of the equipment. They must therefore be informed that the documents exist and consequently be educated in the regulations before applying them.

\section{Standardised training of radiation safety regulations in SA}

The responsibilities of licence holders of medical X-ray equipment are listed in the 'Code of practice for users of medical X-ray equipment. ${ }^{\left[{ }^{[7]}\right.}$ Apart from equipment requirements, the licence holder and responsible person must ensure that those who are occupationally exposed to ionising radiation (radiation workers) are identified and issued with personal radiation monitoring devices (PRMDs). Diagnostic radiographers employed in radiography departments and radiography students in training, who are occupationally exposed to radiation, are therefore radiation workers. ${ }^{[4]}$

The code further mandates that every radiation worker receives 'education regarding the risks and safety rules of ionising radiation; that protective clothing, devices and equipment are provided and properly used; radiation safety rules are communicated to and followed by all personnel; operational procedures are established and maintained to ensure that the radiation exposure to workers, patients and public is kept [as low as reasonably achievable] ALARA without compromising the diagnostic efficiency of the result; and lastly, that workers are educated in the hazards and risks of ionising radiation. ${ }^{\text {[7] }}$

Entry-level radiation workers, e.g. 1st-year radiography students, are legally required to be monitored and issued with PRMDs (commonly referred to as dosimeters) as soon as they are placed in clinical practice. No standardised monitoring of the required education is currently in place. The dosimeter can be ordered from the Radiation Protection Service (RPS) of the SA Bureau of Standards (SABS). The only DRC requirement before registration as a radiation worker and subsequent issuing of the dosimeter, is that a new radiation worker must undergo a medical examination to determine fitness to work. ${ }^{[7]}$ This implies that a licence holder may order dosimeters without submitting proof of education of radiation workers regarding ionising radiation safety. The concern is that the responsibility of the training institution is not signified, which may be the reason for the lack of vigilance observed in clinical practice in terms of the application of certain radiation safety principles.

Radiography training institutions have different policies regarding the training and issuing of dosimeters to 1st-year radiography students. As a rule, the department in which the student is placed for clinical practice is responsible to register the radiation worker and order the dosimeters. The status quo at one training institution may be that the clinical department issues the dosimeters, while the training institution in due course incorporates the radiation safety lectures combined with a radiation protection test. In another setting, dosimeters may be issued within the first week of clinical practice, only to lecture on the academic aspects of dosimeters and radiation risks over the course of a year. These varying procedures result in an unfavourable situation, where the training institution places the radiation safety responsibility of the radiation worker solely on the hospital or practice where the 1st-year student is assigned to for workplace learning. The education of these members of staff regarding radiation is not formally monitored in most hospitals. ${ }^{[9]}$ The researcher observed ignorance regarding the wearing of dosimeters, confirming that human error must be considered. ${ }^{[10]}$

The responsibilities of licence holders of X-ray equipment are further outlined in the 'Requirements for licence holders with respect to qualitycontrol tests for diagnostic X-ray imaging systems. ${ }^{[8]}$ This document emphasises the acceptance and quality-control tests of diagnostic X-ray equipment. Since 31 March 2009, an inspection body, approved by the DoH or an appropriately trained professional registered with the Health Professions Council of South Africa (HPCSA) as a medical physicist, must perform all the acceptance and routine tests. Radiographers, however, are responsible for the routine tests; it is important that they are not only familiar with the requirements, but also equipped to perform thse tests, interpret the tests and adjust necessary parameters to maintain safety on a daily basis. The training must therefore include quality testing of X-ray equipment.

The Central University of Technology (CUT) in Bloemfontein, SA, had the privilege to engage in a curriculum review process that led to CUT being one of the first training institutions for radiography in the country to implement a 4-year qualification in radiography in 2014. The curriculum development process provided an opportunity to determine appropriate content for the radiation safety and quality-control requirements training module. By using the Delphi technique, content was confirmed for basic outcomes for 1st-year radiography students (representing the entry-level radiation worker issued with a dosimeter), and advanced outcomes for 3rdyear radiography students (representing the licence holder, responsible person and qualified radiographer). The development of teaching and learning activities and assessment strategies for radiography radiation safety based on the findings of the Delphi survey will be reported in separate publications.

\section{The Delphi technique}

In this study, the Delphi technique was used to reach consensus ${ }^{[11]}$ on the content of the radiation safety regulations training course. The technique differs from other methods of gathering data from a group of people, as it involves a research team, who are involved collectively with the goal of enhancing the quality and utilisation of the research. ${ }^{[1]}$

The Delphi technique is a decision-making process that has been used for planning and collective decision-making, not only in the field of technology, but also in healthcare and education. ${ }^{[12]}$ In the decision to use the Delphi technique, we took cognisance of two inferences, i.e. that decisions are more valid if the judgement of a group of people is involved, and the possibility that the group members may be influenced by one another if decisionmaking occurs in the presence of the group. ${ }^{[13]}$

A study by Skulmoski et al. ${ }^{[14]}$ indicates that because of the flexibility of the Delphi process, the method may be adapted creatively for most studies. Their study provides proof of numerous three-round studies with successful 
effects. The current study, however, required four rounds. In the fourth round, the panellists were informed that if they wished they could change their opinion. Stability in this study was declared when participants did not change the selection in more than one round. ${ }^{[15]}$

The Delphi technique was used in this study to establish a set of criteria needed for the development and implementation of a training course for diagnostic radiography students. The process involved a quantitative approach that was appropriate for determining the objectives for the radiation safety training course. On the Delphi questionnaire the participants had to respond by making choices between various statements; they were granted opportunities to add comments or suggestions. The latter gave the panellists an opportunity for inductive reasoning and to make unique contributions. ${ }^{[16]}$ The questionnaire encouraged expression of the expert opinion of the panellists by indicating in the information document that the responses would be incorporated in follow-up rounds. The controlled anonymous feedback is a positive characteristic of the process, rendering it suitable to receive feedback from individuals who are physically separated. ${ }^{[17]}$

\section{Method}

Data collection entailed a Delphi process that was mainly quantitative, with an invitation to panellists to add comments or suggestions. The qualitative findings were reported by incorporating the comments in the follow-up rounds of the Delphi process. The research was aimed at improving the current practice of radiation safety training of radiographers and was, therefore, considered action research. ${ }^{[18]}$ The processes of action and research was integrated because the teaching activities and assessment were developed after the Delphi survey and aligned with the criteria accepted through the Delphi process. ${ }^{[18]}$

\section{Participants in the Delphi questionnaire}

The 10 participants in the Delphi questionnaire were experts in the field of diagnostic imaging. The panel included lecturers at higher education institutions involved in radiography training, medical physicists involved in quality tests in diagnostic departments, diagnostic radiography managers of radiography departments and the DRC. The researcher selected the Delphi participants based on the expected value they would add to the study. ${ }^{[18]}$ The sample consisted of 10 individuals from several institutions that consented to participate in the Delphi process, including male and female participants considered knowledgeable in the code of practice for users of medical X-ray equipment and the DoH requirements for licence holders of diagnostic imaging systems. The lecturers were involved in the modules pertaining to radiation protection, and the radiography managers were involved in quality control of medical imaging systems.

\section{Ethical approval}

Ethical approval for this project (ref. no. ECUFS 74/2013) was obtained from the Ethics Committee, Faculty of Health Sciences, University of the Free State (UFS). The Delphi procedure was commenced with an invitation letter regarding the purpose of the study, the process and the duration of the study; the participants gave written consent upon receipt of the invitation. ${ }^{[18]}$ Each participant's response was colour coded to reflect anonymity.

\section{Compilation of the Delphi questionnaire}

The SA DoH requirement statements for licence holders of medical X-ray equipment, contained in the 'Code of practice for users of medical X-ray equipment $^{\text {'[7] }}$ and 'Requirements for licence holders with respect to qualitycontrol tests for diagnostic X-ray imaging systems ${ }^{[8]}$ were presented as 418 criteria in the Delphi questionnaire. Each statement had to be evaluated for inclusion in a basic training course before dosimeters could be issued to the beginner radiation worker, or the advanced training course for the potential licence holder of X-ray equipment. The options were stated on a 4-point Likert scale. These points were defined as follows: $1=$ both courses; $2=$ basic only; 3 = advanced only; and $4=$ none. The layout of the questionnaire was divided into the following sections:

1. General definitions and licensing conditions $(n=84)$

2. Responsibilities of licence holders/responsible person $(n=18)$

3. Operators of equipment and radiation workers $(n=38)$

4. Radiation protection of patients $(n=81)$

5. Radiation protection for the radiation worker $(n=77)$

6. Quality-control tests for diagnostic medical systems $(n=94)$

7. The training course $(n=26)$.

Space was provided for comments for each specific statement and at the end of the section for additional comments deemed necessary by the panellists.

\section{Section 1. General definitions and licensing conditions}

This section dealt with the requirements and recommendation documents for radiation safety associated with the use of medical diagnostic X-ray equipment. It also dealt with the licensing conditions for medical X-ray equipment, with specific reference to the requirements of the apparatus for diagnostic use. The adherence to specific conditions for premises of $\mathrm{X}$-ray equipment was stated in detail. This section was divided into three subsections, each containing various statements $(n=84)$.

\section{Section 2. Responsibilities of licence holders/responsible person}

This section dealt with the responsibilities of licence holders or appointed responsible persons. It contained various statements $(n=18)$.

\section{Section 3. Operators of equipment and radiation workers}

This section dealt with the operators of diagnostic X-ray equipment, with specifics on the application and monitoring aspects of radiation workers. The issuing of the personal monitoring device with the detailed threshold dose limits for radiation workers received attention in this section. It was divided into two subsections, each containing various statements $(n=38)$.

\section{Section 4. Radiation protection of patients}

This section dealt with the basic radiation principles for the public. The importance of justification, optimisation and limitation in managing ionising radiation was stated in order to adhere to the ALARA principle. This section was divided into four subsections, each containing various statements $(n=81)$. The statements referred to general radiography, fluoroscopy and CT.

\section{Section 5. Radiation protection for the radiation worker}

This section dealt with the basic radiation principles and personal monitoring devices for the worker. The statements dealt with the identification and application of principles and techniques to lower the radiation dose to staff in the healthcare environment. The care of the monitoring device with regard to optimal use was also specifically stated. This section was divided into two subsections, each containing various statements $(n=77)$. 
Section 6. Quality-control tests for diagnostic medical systems

This section dealt with the requirements for licence holders with regard to quality-control tests for diagnostic imaging systems. The recording, interpretation and management of the results of the tests received meticulous focus. The frequencies of the tests were listed for diagnostic, CT and mammography equipment. This section was divided into four subsections, each containing various statements $(n=94)$.

\section{Section 7. The training course ${ }^{\star}$}

This section dealt with the training course presentation and assessment. The statements dealt with the learning and teaching activities for the basic and advanced courses in terms of the presentation, either online or in a classroom setting. This section contained various statements $(n=26)$. The percentage of participants making a specific choice on the Likert scale is indicated as selecting either 'Strongly agree,' 'Agree', 'Disagree' or 'Strongly disagree'; e.g. $1=80 \% ; 2=0 \% ; 3=20 \% ; 4=0 \%$, with $1,2,3$ and 4 referring to the respective terms on the scale in the order mentioned above.

\section{Results}

The researcher manually prepared the analysis of the various rounds of the Delphi process. The researcher also entered all quantitative responses in Microsoft Excel (USA) for calculation of consensus and stability and the development of the questions for the next round. The qualitative data were categorised into themes to make an identifying summary. These common themes were added in the next round as additional criteria items. The new items were incorporated in the following round and communicated as such to the panellists. Every round served to refine the results of the previous rounds. ${ }^{[1]}$

A response rate of $100 \%$ was obtained in all four rounds of the Delphi process. Consensus was reached when $80 \%$ of the panellists agreed on a certain criterion. ${ }^{[19]}$ Consensus was reached on 309/418 (74\%) statements in the questionnaire. Among the 418 statements, consensus was reached on 13 selections for both basic and advanced training and assessment, 131 selections for basic training and assessment, and 137 selections for advanced training and assessment, with no exclusion of any statements from the training and assessment.

Stability was determined on completion of the fourth round. Linstone and Turoff ${ }^{[15]}$ describe stability as the tendency of expert opinions to merge when there is stability in the movement of the group's responses. Stability, which may be declared when movement of opinion of the group as a whole has reached stability, was acquired with regard to the remaining $26 \%$ of statements.

\section{Discussion and recommendations}

The relatively high degree of consensus and stability, combined with no statements being excluded from the training and assessment by a diverse group of panellists, support the appropriateness of the conclusions drawn from these data.

The comments from the Delphi panellists regarding the content of radiation safety and assessment provided insight that guided the researcher to consider important aspects, e.g. the basic training must address the awareness of principles, and the advanced training must engage the student in more in-depth training. Section 7 of the Delphi questionnaire dealt with the presentation of the training and the panellists' opinions on the assessment of radiation safety. The panellists strongly agreed that all the criteria on which consensus was reached in the survey had to be included in both the basic and advanced assessment. They also agreed that the Delphi questionnaire covered all the aspects required to use diagnostic X-ray equipment safely, with the comment that it was comprehensive without the guarantee of completeness. The panellists strongly agreed that successful completion of the basic and advanced training should be confirmed by assessment, and that the score to indicate successful completion of both assessments should be a minimum of $75 \%$.

The panel disagreed that distance learning was appropriate for basic training, as students need hands-on training. The panel did not reach consensus on the appropriateness of distance learning for advanced training. They disagreed that the student would master the content of the training by self-learning and added specifically that there was a need to execute the tests, and that evidence should be recorded for the advanced students. The panellists strongly agreed that content on risks of radiation and interaction of radiation and tissue had to be included in the basic training.

Further comments from the panellists included that insight in the workload should be evenly distributed between the training, and that the advanced training should build on criteria for the basic training. The information contained in the training was regarded as necessary for different reasons, including professional, clinical, or compliance. Repetition of the content, according to the panellists, would ensure a high degree of understanding and recollection. Information was allocated to the basic training, which the students could use immediately, but information on technical equipment and structural specifications was recommended for the advanced training. The concluding comments addressed the need for supervision and monitoring for both trainings to ensure that correct quality tests were carried out and that candidates gained understanding of acceptable limits of the tests. Flexibility was reiterated in terms of the offering and assessment owing to the reality of scarce resources in SA.

The comments from the panellists provided insight in and guidance for the final list of criteria to be included in either the basic or advanced training and assessment. The comments were incorporated in the teaching and learning activities.

\section{Conclusion}

By involving a panel of experts to determine the content of radiation safety training and the criteria and methods for assessment, the study can make a contribution to the existing body of knowledge in the field of radiography. Furthermore, the training programme has already been found to deliver a better-trained 1st-year student to the radiography profession and practice.

To equip the radiation worker with standardised knowledge and expect from the student to provide standardised evidence of mastery of radiation safety principles and requirements, is a major step to optimally apply the currently neglected ALARA principle in practice.

${ }^{\star}$ Supplementary information. An appendix is available from the corresponding author on request.

Acknowledgements. The authors wish to thank the Health and Welfare Sector Education and Training Authority (HWSETA) for funding, Prof. Driekie HaySwemmer for assistance with the preparation of the article, and Dr Daleen Struwig for final technical and editorial preparation of the manuscript.

Author contributions. BvdM was responsible for the literature search, conceptualisation, design of the training and assessment, and drafting of the manuscript. SK, as the study leader, and MMN, as the co-study leader, revised the manuscript critically. All three authors approved the final version of the manuscript submitted for publication.

Funding. Funding was provided by HWSETA.

Conflicts of interest. None. 
1. Perez M. Enhancing radiation safety and quality in healthcare. Proceedings of the 18th ISRRT World Congress, 12 - 15 June 2014, Helsinki, Finland. http://portfolio-web.ess.fi/www/SuomenRontgenhoitajat/2014_ISRRT/\#/1 (accessed 23 June 2017).

2. International Atomic Energy Agency. Radiation protection and safety of radiation sources: International basic safety standards. IAEA Safety Standards Series GSR Part 3. Vienna: IAEA, 2014. http://www-pub.iaea.org/books/ IAEABooks/8930/Radiation-Protection-and-Safety-of-Radiation-Sources-International-Basic-Safety-Standards (accessed 23 June 2017).

3. Vaño E, Rosenstein M, Liniecki J, Rehani M, Martin CJ, Vetter RJ. Education and training in radiological protection for diagnostic and interventional procedures. ICRP Publication 113. Ann ICRP 2009; 39(5). http:// www.icrp.org/publication.asp?id=ICRP\%20Publication\%20113 (accessed 20 June 2017).

4. South African Government. Hazardous Substances Act, 1973 (Act No. 15 of 1973). Government Gazette No. 3834:550. 1973

5. International Commission on Radiological Protection. The 2007 recommendations of the International Commission on Radiological Protection. ICRP Publication 103. Ann ICRP 2007;37(2-4).

6. South Africa. Regulations: Control of electronic products. Government Gazette No. 3991, 1973. (Published under Government Notice R1332.) https://docs.google.com/file/d/0B5d_I5LIOhwTYzZjY2IIZDEtOWQwMy00YjU5LTg1ZDQtNzNmMTkzNzdkZjU4/edit?pli=1 (accessed 20 June 2017).

7. Department of Health. Directorate: Radiation control. Code of practice for users of medical X-ray equipment. 2011. http://www.scribd.com/doc/33826566/Department-of-Health\#scribd (accessed 23 June 2017).

8. Department of Health. Directorate: Radiation Control. Requirements for licence holders with respect to quality control tests for diagnostic X-ray imaging systems. 2012. http://rssa.co.za/alerts/department-of-healthdiagnostic-quality-control.html (accessed 23 June 2017).
9. Van der Merwe B. Radiation distribution in a private neurological theatre during invasive back pain management procedures. MHPE. Bloemfontein: Central University of Technology, 2008

. Herbst CP, Fick GH. Radiation protection and the safe use of X-ray equipment: Laws, regulations and responsibilities. S Afr J Radiol 2012;16(2):50-54. https://doi.org/10.4102/saj.v16i2.306

11. Du Plessis E, Human S. The art of the Delphi technique: Highlighting its scientific merit. Health SA Gesondheid 2007;12(4):13-24. https://doi.org/10.4102/hsag.v12i4.268

12. Loo R. The Delphi method: A powerful tool for strategic management. Policing. Int J Police Strat Manage Loo R. The Delphi method: A powerful tool for strategic man
2002;25(4):762-769. https://doi.org/10.1108/13639510210450677

13. Murray JW Jr, Hammons JO. Delphi: A versatile methodology for conducting qualitative research. Rev Higher Educ 1995;18(4):423-436. https://doi.org/10.1353/rhe.1995.0008

14. Skulmoski GJ, Hartman FT, Krahn J. The Delphi method for graduate research. J Inform Technol Educ 2007;6:1-21. 15. Linstone HA, Turoff M. The Delphi Method: Technique and Application. London: Addison-Wesley, 1979.

16. Cottrell RR, McKenzie JF. Health Promotion and Education Research Methods. Sudbury: Jones and Bartlett, 2011.

17. Nel CPG. A framework for achieving excellence as a clinical educator in the School of Medicine, University of the Free State. MHPE. Bloemfontein, University of the Free State, 2007.

8. Denscombe M. The Good Research Guide. 3rd ed. Maidenhead, UK: Open University Press, 2007.

19. Larson E, Wissman J. Critical academic skills for Kansas Community College graduates: A Delphi study. Commun Coll Rev 2000;28(2):43-56. https://doi.org/10.1177/009155210002800203

Accepted 21 February 2017. 